\title{
Study on the Countermeasures of Local Colleges and University in Henan for the Preservation and Inheritance of Intangible Cultural Heritage of Folk Fine Arts
}

\author{
Xiaofei Zhang \\ School of Art and Design \\ Huanghe Science and Technology College \\ Zhengzhou, China \\ e-mail:359163743@qq.com
}

\begin{abstract}
This paper analyzed the advantages of colleges and universities in the preservation and inheritance of intangible culture and put forward the strategy how to fully mobilize and maximize the professional advantages of local colleges and universities in Henan for the relative subjects and major of fine arts and how to carry forward and develop the intangible cultural heritage of folk fine arts in Henan, so as to give a full play to the role of local colleges and universities in educating people and promoting the effective inheritance of Central Plains culture.
\end{abstract}

Keywords-intangible cultural heritage; folk fine arts; local colleges and universities; protective inheritance; countermeasures

\section{INTRODUCTION}

Higher fine arts education keeps a symbiotic relationship with the preservation of intangible cultural heritage of folk fine arts, which are interacting and developing mutually and commonly. The symbiotic development is mutually beneficial to both higher fine arts education and preservation of intangible cultural heritage. On one hand, higher fine arts education, with the preservation of intangible cultural heritage as the carrier, quality-oriented education and special talent training as the objective, cultural inheritance as the purpose, can further enrich the connotation of campus culture construction, enhance young students' understanding of traditional national culture and then promote students' allround development; on the other hand, the preservation of intangible cultural heritage can give full play to the advantages higher art education has in talent and scientific research and take reasonable and scientific protective measures for better inheritance of traditional national culture depending on the discipline construction, playing a positive role in the promotion of cultural and ideological progress of human beings and the protection of cultural diversity.

Fund Project: Fund Project for Young Backbone Teachers from Colleges and Universities in Henan "Study of Inheritance of Folk Fine Arts Intangible Cultural Heritage in Henan" (project No.: 2011GGJS-221).

\section{ANALYSIS ON THE ADVANTAGES OF LOCAL COLLEGES AND UNIVERSITIES IN HENAN FOR THE PRESERVATION AND INHERITANCE OF INTANGIBLE CULTURAL HERITAGE}

As of 2014, the total number of colleges and universities around Henan Province has reached 121, among which, more than 40 colleges and universities have established undergraduate programs for fine arts and design. Overall, for the preservation of intangible cultural heritage, colleges and universities in Henan have unique advantages in the following areas combined with the characteristics of intangible cultural heritage in this province:

\section{A. The Local Colleges and Universities are Numerous and}

Geographically Distributed Near the Birthplaces,

\section{Facilitating the Research Work}

The colleges and universities are distributed in all cities of Henan Province, and substantially, you can find colleges and universities in all birthplaces and transmission areas of intangible cultural heritage. Local colleges and universities which typically have a relatively exact understanding of local people's living conditions and recognize their value accurately, can understand and collect the data and information about history and status quo of intangible cultural heritage project with ease, so local colleges and universities have a distinct geographical and regional advantage no matter for collection of information related to local projects, field investigation or the understanding and cognition of such intangible cultural heritage.

\section{B. Local Colleges and Universities Bring a Large Number of Talents Together, Making It Easier to Build the Teams and Giving Full Play to Their Advantages}

Colleges and universities are the places where talents gather and talents who are engaged in various disciplines related to intangible cultural heritage including art, history, social science, literature and so on are allowed to carry out research on the preservation of intangible cultural heritage 
from their respective academic visions. In recent years, may experts and scholars from colleges and universities in Henan have participated in the preservation work of intangible cultural heritage increasingly frequently, and these welleducated, thoughtful and enthusiastic people are labeled as an important force on which we must and shall rely for the implementation of the preservation of intangible cultural heritage.

\section{Local Colleges and Universities have a Powerful Foundation Platform for Scientific Research, Providing Academic Support for the Preservation of Intangible Cultural Heritage}

Intangible cultural heritage project requires for an intensive theoretical and practical research on its forms, features, attributes and other multiple aspects, so the preservation of intangible cultural heritage is dependent on the support of correlation theory. The experts, scholars and classroom teachers all have advanced and critical thinking skills and cultural ideas, powerful abilities to transform excavation, collection and other basic work into theoretical research and then further carry on and develop the research object, for this reason, colleges and universities have an advantage in theoretical research. At present, colleges and universities around Henan have established a large number of cultural institutions for cultural inheritance and innovative development in combination with the advantage of local historical and cultural resources, including Research Center for Central Plains Cultural Resources and Development and Research Center for the Preservation of Historical and Cultural Heritage of Zhengzhou University, Research Institute for Culture of Song Dynasty and Academy for Folklore and Culture of Central Plains of Henan University, Research Center for the Preservation of Intangible Cultural Heritage in Central Plains and Academy for Historical and Cultural Resources Utilization and Tourism Development in Central Plains of Henan Normal University, Research Center for Oracle Bones Studies and Yinshang Culture of Anyang Normal University, International Research Center for Heluo Culture of Luoyang Normal University, Research Center for Huaihe River Civilization of Xinyang Normal University, Research Center for Han Culture of Nanyang Normal University, etc..

\section{Local Colleges and Universities Serving as the Cultural Information Center, have a Distinct Advantage in Dissemination and Exchange of Resources}

Colleges and universities have places for collection and conservation of research resources, such as libraries, museums and so on. Convention for the Safeguarding of the Intangible Cultural Heritage highly values the importance of propaganda work and declares that all State Parties are supposed to ensure respect for the intangible cultural heritage of the communities, groups and individuals concerned and endeavor to ensure the widest possible awareness of the threat to intangible culture and implement various activities according to the Convention. Colleges and universities acting as the cultural information center are provided with lecture halls, exhibition halls, auditorium, squares for cultural events and appropriate facilities used for organizing activities for the publicity, display, joint performance, communication of the preservation of intangible cultural heritage.

\section{E. Students Coming from all Regions Promote the Dissemination of Local Intangible Culture in and out of the Province.}

Colleges and universities in Henan bring together not only a large number of local young students but also a considerable number of talents coming from other provinces. Students from this province have strong feelings for the intangible cultural heritage in their hometown. Under the influence and promotion of students from this province and other provinces, the provincial intangible cultural heritage can be disseminated throughout the country. The communication among students from different provinces and cities in the field of intangible cultural heritage helps the promotion and research of intangible cultural heritage in deeper and broader fields.

\section{SUGGESTIONS ON THE COUNTERMEASURES OF} COLLEGES AND UNIVERSITIES IN HENAN FOR THE PRESERVATION AND INHERITANCE OF INTANGIBLE CULTURAL HERITAGE OF FOLK FINE ARTS

\section{A. To Strengthen the Professional Development of Intangible Cultural Heritage with the Multidisciplinary Advantages as a Platform}

Specialty establishment helps promote the development of discipline-oriented intangible cultural heritage. Currently, although some universities have established the specialties oriented to the safeguarding of intangible cultural heritage in the stage of training master and doctor, there is an urgent demand for the undergraduate major in this field. Colleges and universities can establish a specialty in intangible cultural heritage by virtue of discipline and talent advantages based on the associated specialties in related colleges and departments, including the specialty of art design theory and fine arts theory in Higher Institute of Art, the specialty of cultural industry in Faculty of Humanities and so on, and struggle for promotion of professional construction of intangible cultural heritage.

\section{B. To Strengthen the Construction of Courses Related to Intangible Cultural Heritage}

The intangible cultural heritage has a variety of forms and a complete range, covering painted sculpture, tile carving, stone carving, door painting, shadow puppet, paper cutting, embroidery and other art forms. For the regular education and learning of fine arts at colleges and universities, we are supposed to integrate folk fine arts intangible cultural heritage resource into the teaching content to establish a systematic, scientific and reasonable educational mechanism and improve the associated curriculum systems as far as possible, which is an important way for colleges and universities to safeguard and inherit intangible cultural heritage. For example, to establish additional curriculum representing the intangible cultural heritage of our country and Henan Province for the current 
art education, including "Outline of Folk Art", "Introduction to Folk Art of Henan" etc.. The data of folk fine arts intangible cultural heritage around Henan should be discriminated, sorted and then incorporated in teaching content of universities for promoting the development of school-based fine arts curriculum and school-based teaching materials, through which, students' learning and understanding of the resources of local art and culture can be enhanced. Huanghe Science \& Technology College has established a course of "Appreciation of Chinese Folk Art" for the specialty of art design and conducted useful exploration in teaching through teaching research for many years, for example, students are not only taught to appreciate the folk art works to arouse their interests but also directed to make their own folk art works, such as paper cutting, shadow puppet, clay sculpture and so on. Since folk art works featuring self-entertainment are made by ordinary working people, students can really understand and grasp the essence of some folk art when being engaged personally in its production.

\section{To Develop Special Courses for Intangible Cultural Heritage of Folk Fine Arts Based on the Local Conditions}

Many fine arts intangible cultural heritages of Henan Province which are characterized by rich cultural deposit and perfect art form after the historical accumulation are worthy of specialized absorption, research and inheritance. They have gradually developed a complete and unique set of production method, craftsmanship and art form in the process of continuous development and inheritance from generation to generation since its initial formation. Intangible cultural heritage is unknown to the outsiders in many areas because it is especially inherited in a closed way. With an increasing openness of society, some intangible cultural heritages are gradually revealing their secret parts, providing people with an opportunity to maintain close contact with it, and therefore, the scientific research personnel in colleges and universities have invited local intangible cultural heritage inheritors to classrooms to give special lessons, and in this way, interested students can deeply experience and learn these valuable national cultural heritages.

\section{To Cultivate Innovative Fine Arts Talents at Colleges and Universities, to Promote the Inheritance of Intangible Cultural Heritage}

Inheritance is fundamental. It is the educators' priorities at colleges and universities to purposefully and systematically bring things related to intangible cultural heritage into education and teaching and take effort to find an entry point and a binding point. Students should be organized to apply a variety of elements of fine arts intangible cultural heritage for artistic creation. The intangible cultural heritage of Liaoning Province itself can be used as symbolic and creative elements of fine arts creation by virtue of its cultural traits of Liao Style and distinct regional characteristic. These artistic techniques and art forms with unique brilliance make it easier for students to understand and interpret intangible cultural heritage with a modern aesthetic judgment and boldly utilize and innovate it for art design and fine arts creation.

\section{E. To Foster the National Artistic Spirit with the Second Classroom of Art Education as an Extended Carrier Including Cultural and Art Activities on Campus}

Colleges and universities shall mobilize and integrate human power and material resource to carry out a variety of special art activities featuring a profound artistic connotation, for example, for fine art discipline, colleges and universities can implement colorful activities including expert lectures special for fine arts intangible cultural heritage, exhibition of local art and culture resources, traditional local culture $\&$ arts festival, etc., or regularly invite old artists to show their unique skills to college students on campus, which can arouse students' interest more effectively in an intuitive and convincing way and deepen students' understanding of intangible cultural heritage. In addition, it is advisable to establish relevant associations for intangible cultural heritage, like association for folk paper cutting, association for folk clay sculpture, etc.

\section{F. To Extend the Preservation and Development of Intangible Cultural Heritage beyond Schools Through the Team Organization of College Students' Social Practice}

Ethnic or folk art has regional characteristics which are the spatial feature for the formation and development of ethnic art and folk art, while students in a college are a community composed of groups from different regions and different nationalities, exactly corresponding with the situation where intangible cultural heritage is widely distributed. After learning the curriculum correlated to intangible cultural heritage, students can conduct an investigation on related cultural heritage and inherited learning of folk art, and this can be easily achieved if the curriculum and activities associated with intangible cultural heritage at universities have attracted students' interests, because the ethnic or folk art forms investigated and learned by students in life can be found in their hometowns or around them or even are specialties of their parents.[1]

\section{G. To Strengthen the Preservation of Intangible Cultural Heritage and Coordinated Development of Cultural Industries with the Cooperation of Industry, Learning and Research as a Carrier}

Colleges and universities are supposed to rely on regional and their rich cultural resources for the higher fine arts education, to strengthen the cooperation with local government and cultural enterprises and to endeavor to establish an mode for the integrative development of intangible cultural heritage, regional cultural industry and economy so as to achieve a win-win-win result for high fine art education, preservation of intangible cultural heritage and regional economy and culture.

Colleges and universities must enhance cooperation of fine arts education with regions where intangible cultural heritage exists, establish colleges students' education and 
research base for intangible cultural heritage and creative industrial base for intangible cultural heritage, strengthen and promote the protection and exploitation of the intangible cultural heritage. On the one hand, colleges students can feel the charm of traditional national culture when participating in social practice and being engaged in the protection of intangible cultural heritage in such bases, helping promote the formation of national cultural consciousness; on the other hand, intangible cultural heritage can be activated by encouraging the active participation of teachers and students at colleges and universities and full utilization of local rich cultural resources, and based on that, we are supposed to conduct cultural innovation for the industrialization of the intangible cultural heritage, so that social benefits and economic benefits can be highly unified. As Chen Mengxin and Zhang Xin advocated in the "Overview of First Seminar on Education and Teaching of Intangible Cultural Heritage at Chinese Colleges and Universities" that all colleges and universities throughout the country should take a view of national cultural integration to actively and urgently perceive their own cultural resources in the mentality of national cultural integration, in particular, institutions of higher education located in regions rich in cultural resources should play a bridging role in the preservation and inheritance of local cultural heritage and development of cultural productivity. We shall not see academic research as a closed research featuring a single text-based, college-oriented and one-way form or split it from the research on living culture, but make academic research useful for social development, transform the protection of cultural resources into an important bridge for its sustainable development and maintain the healthy and vibrant cultural development".[2]

\section{H. To Promote the Protection Project of Intangible Cultural Heritage Depending on the Cultural Resource Libraries of Colleges and Universities}

Intangible cultural heritage has an extremely wide variety of items, covering not only tangible cultural heritage but intangible cultural heritage, and any kind of audio recording and video, photography, text data or tool, appliance, handicraft or other tangible materials are in need of protection, so it is necessary to give full play to the role of the existing archives, libraries and modern information network equipment at colleges and universities. Firstly, colleges and universities shall focus on the use of modern equipment and facilities to save the results and systematically record and store the intangible cultural heritage data when collecting data in traditional means and tools. Secondly, in the process of sorting and saving intangible cultural heritage data, attention should be paid to information and data sharing of intangible cultural heritage. An open platform for the information exchange of intangible cultural heritage should be established among colleges and universities to integrate data and information of intangible cultural heritage obtained by each school and to share part of data which can be shared among platforms. [3]

The combination of intangible cultural heritage protection and higher education is a complex and systematic project, requiring the joint efforts of all parties. Higher fine arts education is one of the important ways to safeguard intangible cultural heritage and plays an irreplaceable role no matter in the preservation of intangible cultural heritage or the development of intangible cultural heritage. Similarly, the introduction of intangible cultural heritage protection into higher fine arts education system, on the one hand, enriches the cultural resources, teaching means and methods, and on the other hand, plays an active role in the quality-oriented education of college students. Both of them promote, complement and develop mutually.

\section{REFERENCES}

[1] Chen Youlin. Study of Art Education of Universities as an Effective Way to Protect and Develop Intangible Cultural Heritage [J]. Journal of Sichuan College of Education. 2010 (08): 12

[2] Chen Mengxin, Zhang Xin. Overview of First Seminar on Education and Teaching of Intangible Cultural Heritage at Chinese Colleges and Universities [J] Journal of Hubei College of Art, 2002 (04): 61-62.

[3] Luo Hao. Study of the Countermeasures of Colleges and Universities for the Preservation of Intangible Cultural Heritage $[\mathrm{J}]$ The South of China Today.2009 (09): 12 